\title{
Conceptualizing an expanded role for $\mathrm{RNs}$
}

\section{Glenn Donnelly, Liz Domm}

Faculty of Nursing, University of Regina, Regina, Canada

Email: Glenn.Donnelly@uregina.ca

Received 21 November 2013; revised 1 January 2014; accepted 23 January 2014

Copyright (c) 2014 Glenn Donnelly, Liz Domm. This is an open access article distributed under the Creative Commons Attribution License, which permits unrestricted use, distribution, and reproduction in any medium, provided the original work is properly cited. In accordance of the Creative Commons Attribution License all Copyrights (C) 2014 are reserved for SCIRP and the owner of the intellectual property Glenn Donnelly, Liz Domm. All Copyright (C) 2014 are guarded by law and by SCIRP as a guardian.

\section{ABSTRACT}

In our changing health care system, the role of registered nurses (RNs) has become indistinguishable from other nursing and health care providers' roles. The purpose of this research was to explore the perspectives of nurse leaders and direct care RNs about the existing and future RN scope of practice. This research used an interpretive description analysis on data that was garnered from nurse leaders and RNs through separate focus groups. Participants identified existing threats to their roles, examined their scope of practice and proposed changes to the RN scope of practice. Specific areas that were identified included leadership, advocacy and expansion of RNs practices were dominant themes.

\section{KEYWORDS}

\section{RN Role; RN Scope of Practice; RN Domains of Practice}

\section{INTRODUCTION}

On a busy hospital ward, nursing staff are occupied with patient care. As observers, we wonder which of the staff are registered nurses $(\mathrm{RN})$. We try to differentiate the various categories of nursing personal, but it seems that the licensed practical nurse (LPN) and RN are interchangeable in the visible functions they carry out. With advances in training, LPNs scope of practice expanded, and we question if and what commensurate changes have occurred with RN practice? I approached a RN and asked her how her practice has changed. She responded quietly “The licensed practical nurses' scope of practice is the same as ours. When I raised concern, I was accused of being territorial so now I am just trying to hold on to my job-now that the budget is tight, they don't need to pay me my wage, when an licensed practical nurse can do the same thing for less money”. The RN expressed her perception that her employers want nurses individually and collectively to "get the job done" [1], rather than stop work to question scope of nursing practice.

Traditionally, the Licensed Practical Nurse (LPN) worked under the supervision of the RN, as supported in provincial legislation. With changes in legislation, LPNs no longer work under the supervision of the RN. This has resulted in a lack of clarity in the differences between $\mathrm{RN}$ and LPN roles and scope of practice.

Registered nurses and licensed practical nurses are mandated by their professional associations to work to their full scope of practice. Registered nurses' associations provide documents to explain the full scope of RN practice, [2-4] but these documents are often ambiguous and do not provide the guidance needed by RNs. Even more disturbing is the perception by the public, patients, and health care administrators of inter changeability between RN and LPN practice. This perception underlines registered nurses' belief that much of RN work is invisible. The critical cognitive functions prompting RN nursing assessments and actions are difficult to describe, and may remain unexplained by RNs.

There is scant literature assessing the ability of RN to articulate RN domains in their scope of practice. Similarly, an understanding of RN roles from a policy and health human resource planning perspective is lacking. The absence of clearly articulated RN roles or domains in healthcare literature points to a significant need for $\mathrm{RN}$ to articulate their perspective of $\mathrm{RN}$ roles and domains of practice in a meaningful manner. Professional accountability necessitates clarity on who is educated and prepared to safely do what nursing functions to whom and under which circumstances [5].

Since the time of Florence Nightingale, nurses have attempted to define what their practice is. Nurse scholars, nurses' regulatory associations, and nurses' employers have contributed to definitions of nursing. Despite these 
attempts, when contemporary RN are asked "what is registered nursing?” few RNs can articulate the essence of the profession or the range and depth of domains of their practice. According to Gordon (2006), this gap exists because RNs have been socialized to emphasize their virtues rather than their knowledge, and to wear their hearts, and not their brains, on their sleeves. The ongoing attempt of registered nurses to define what they do rather than by what they know (Parish, 2001) perpetuates the stereotype of silent physician assistants "requiring no skill or intellect” [6]

The RN role has advanced from 'attendant of the sick' and 'teacher of hygiene' to the fulfillment of many diverse roles in today's complex care environments” [7]. However, confusion about what are registered nursing domains of practice persists. Schlotfeld asserted "There can be little doubt that one of the highest priorities for creating an appropriate future for nursing is that of identifying, structuring, and continuously advancing the knowledge that underlies the practise of professionals in the field” [8].

\section{ROLE OF THE REGISTERED NURSE}

With RN practice governed by legislation, one may question why the public and RNs do not hold a more robust understanding of the $\mathrm{RN}$ role. This may be influenced by a scarcity of literature describing RN scope of practice in terms of knowledge utilization and critical thinking. RN roles are frequently described in terms of task performance and checklists [9]. Blais created a document for a Canadian health authority with a chart entitled "Frequently Asked Questions about the Registered Nurse Scope of Practice”, which addresses RN competencies to perform particular tasks in various circumstances, such as sharp debridement, adjustment of insulin dosage, or administration of a narcotic antidote without an order [10]. The depth and breadth, or scope of $\mathrm{RN}$ practice as a professional utilizing the knowledge, skill and judgement they are educated to provide is not addressed in the document. Similarly, the Board of Registered Nurses of California published "An Explanation of The Scope of RN Practice, Including Standardized Procedures" which answers questions about RN functions such as 1) liability insurance for general principles of registered nurse practice, 2) who can use the title “nurse”, 3) general medication questions, and 4) general questions on registered nurses' management of pain [11]. This document does not address the essence of what RN practice is or the unique $\mathrm{RN}$ role and contribution within the healthcare system.

Nursing jurisdictions in Canada develop documents describing the $\mathrm{RN}$ role in terms of education level related to the practice context, comparisons of practice expecta- tions of RN and LPN, and levels of responsibility [12,13]. These documents define the role of the registered nurse in terms of level of decision making, identifying conditions through assessments and nursing diagnoses, leading and coordinating the care planning process, monitoring and interpreting changes in the client condition and responding to the identified changes with appropriate interventions. Other jurisdictions have defined RN roles in terms of client factors, nurse factors and environmental factors [14]. In this regard, the College of Nurses of Ontario (CNO) differentiates RN scope of practice from the LPN' role in client care', which is rated on a continuum from stable to complex; "nurse factors", which define the practice expectations of the RN and LPN; and "environmental factors" which include practice supports such as the existence of policies and procedures, ratio of expert to novice nurses on the unit, the proportion of nurses familiar with the unit, level of consultation resources available, and the stability and predictability of the care environment including rate of client turnover and level of predictable events. Despite the College of Nurses of Ontario (CNO) documents meant to clarify the $\mathrm{RN}$ role, the unique role and contribution of the $\mathrm{RN}$ is not visible and employers continue to use the RN and LPN interchangeably. Identical RN and LPN job descriptions except for the mention of coordination of care being $\mathrm{RN}$ responsibility support this penchant for interchange ability.

Historically, each category of nurses had clearly defined roles and responsibilities, supported in provincial legislation, and a hierarchy of nurses' functions were evident with RNs directing care and LPNs working under the direct supervision of an RN. However, changes in legislation with removal of the reference to supervision, and professional nursing associations' documents extolling nurses' collaborative care [15] led to unclear roles and responsibilities for many nursing professionals. This may be associated with rapidly evolving educational programs, increased entry to practice requirements by regulatory bodies, legislative changes to nursing acts, and an unprecedented shortage of registered nurses. Additionally, healthcare reform during the 1990s reduced the number of RN positions at all levels including front line, administration/management, education and research [16]. As a result, healthcare managers get minimal information regarding the roles of professional nursing personnel and cannot rely on this information to determine appropriate staff and skill mix to ensure the provision of quality client care [17]. As identified by Canadian Health Services Research Foundation (CHSRF) "Appropriate nurse staffing involves more than just the number of nurses on duty. Education, experience, skill mix, and leadership qualities have an enormous impact on the quality of nurse staffing” (p. iii). Determining nurse staffing is complex and entails understanding the needs of the pa- 
tient and the "matching of human resources" to meet those needs [16].

Research about RN roles in speciality areas of practice offers little insight into RN roles beyond task description. Swan, Conway-Phillips and Griffen (2006) described the $\mathrm{RN}$ roles in ambulatory care settings were toorder supplies, locate records, find equipment, assist with procedures, and chaperone during procedures. Although authors of this study offered information for future dimensions of the staff nurse role, the RN role description in this setting falls short of drawing on RNs educational preparation and knowledge for the work [18]. Similarly, the RN role in critical care units in not viewed much differently. Ringer man and Ventura described an initiative to introduce LPNs into a critical care unit due to a RN shortage. The authors reviewed RN and LPN nurse practice acts and compared these to typical care interventions required by critically ill clients in one unit. These authors determined that $55 \%$ of the tasks could be performed by LPNs, therefore unit staffing changed to accommodate LPNs, who were assigned a caseload, and RNs were employed to supervise LPN work [19]. While the authors identify that some RNs had difficulty with the transition from a "task-model" to one of "case manager", there is little evidence that this RN leadership role in critical care improved the quality of client outcomes. Again, initiatives appear to be based on an assessment of task performance versus knowledge application.

\section{THE VOICE OF REGISTERED NURSES}

Research specifically addressing how nurses perceive the $\mathrm{RN}$ role is scarce. Besner et al. conducted a study to elicit information of how the three nursing professions define their scopes of practice and to identify the barriers and facilitators to fulfilling this role. The researchers found, “...considerable role confusion among the three groups of nurses and between nurses and other health professionals, which results in unnecessary overlap in task performance and introduces inefficiency in health care delivery". All three nursing roles were identified by the tasks each performed, while registered nurses, licensed practical nurses and registered psychiatric nurses were unable to articulate a deeper understanding of their role beyond task performance [20].

Nurses frequently understand and define their role in terms of a set of tasks or list of skills, which by tradition circumscribes the scope of practice. Registered nurses frequently lament that other health care workers' actions blur RN practice, such as LPNs, paramedics, or the physician's assistants. Nurses voice frustration with health care management, policy makers and funders (government) because they are required to justify why a RN is required when others can perform many of the same tasks for less pay than a RN.

All too often RNs don't have the language to express the critical foundational values, perspectives and nursing theory which drives their nursing practice. In the absence of RNs articulating a fulsome description of their nursing practice, nurses are seen as simply performing a set of psychomotor skills with little regard to essential functions of the RN roles such as advocacy, counselling and coaching, coordinating, guiding, patient-teaching, assessment and diagnostic functions, as well as administering and monitoring complex technological treatments accurately and safely. The front line RN in a patient care setting detects early signs of impending complications in the patients' condition [21]. Surveillance by RNs involves assessing and monitoring patients for signs of subtle changes over time that signal the onset of complications, implementing nursing actions to prevent complications and promote health, and evaluating nursing care. Evidence suggests that constant surveillance of patients by nurses reduces mortality and life-threatening complications in the hospitalized patient [22]. Canadian registered nurses, who are most often educated with a baccalaureate degree have competencies that allow them to perform these functions. Because RNs are frequently employed in health care organizations and are vulnerable to health care system trends, RNs need leadership and strong communication skills to clearly articulate the value of professional $\mathrm{RN}$ practice.

\section{CONTEMPORARY NURSING PRACTICE}

In the book "Educating Nurses: A Call for Radical Transformation" by Benner, Sutphen, Leonard and Dayan analysis of changes in RN practice highlights the cognitive functions that are required for nursing practice. There has been a shift in responsibility for patient care from physicians to nurses. Physicians are primarily involved in diagnostic activities and are prescribers of treatment regimens. Nurses continuously assess health status for the whole person, and administer and monitor treatment regimens, usually with distant medical consultation, with exceptional skill, knowledge, and judgement. On the basis of the patient's response to treatment, RNs often adjust and titrate therapies, perform complex, precise and diverse technological interventions, and continuously monitor changes in patients' physical conditions that are critical to patient safety and well-being. Good clinical judgment and attentiveness are needed even more with increasing acuity levels and diverse chronic illnesses now commonly present in a rapidly aging population [23].

Registered nurses are prepared to practice safely, thought fully, accurately, and compassionately in a variety of clinical areas where expectations for knowledge 
and innovation are escalating. Safe and effective practice requires an understanding of normal and abnormal pathophysiology, genomics, pharmacotherapeutics, biochemical implications of laboratory medicine for patient therapies, physics of gas exchange in the lungs, cell transport of oxygen in acutely ill patients, the human experience of illness, and normal growth and development [23]. Nursing has advanced in modern society; unfortunately, there is still very little clarification of $\mathrm{RN}$ roles, or differentiation of roles for different categories of nursing.

\section{MOVING NURSING TO A KNOWLEDGE-BASED PROFESSION}

Professional nursing has tried to assume that expanded education requirements and knowledge bases serve to provide the requisite background for nursing to move to knowledge-based practice. Although this notion has been in the nursing literature for some time, main stream nurses have been slow to embrace this value as an identifying feature of their own practice.

This stand has become problematic in that nurses and others continue to define their role based on a set of tasks. It is hardly a surprise that nurses describe their role framed in a specific constellation of skills to perform tasks such as changing a dressing or administering medications. Tasks became a value that nurses embraced as performance standards in which they demonstrated proficiency and expertise. Employers, other health workers and the public have customarily and still understand nursing in terms of the skill set that they possess. One can hardly expect nurses to espouse something other than a skill paradigm when this is and traditionally has been the prevailing belief and value of society [24]. Nelson and Gordon expressed dismay that in the twenty-first century, when there is increasing pressure to link nursing practice to patient outcomes, nurses appear to have a severely limited vocabulary when talking about the importance of their work.

There is growing evidence that supports the critical role of the registered nurse in the health of patients. However RNs tend to hang on to skill lists rather than espouse and articulate their vast amount of knowledge about a wide range of health problems and solutions gained from their education and experience. RNs are rarely consulted on health care issues, even though the public regard RNs as honest and ethical providers of health services [24]. Nelson and Gordon state that even though the public has this belief in registered nurses, the predominant thinking is that nurses have limited knowledge and are often recognized as being virtuous angels [24].

Benner's work in her landmark study "From Novice to Expert Excellence and Power in Clinical Nursing Prac- tice)” re-conceptualized skill lists to the complex area of contextual learning and practice. Her work was and is vital in that it labeled the central activities of nursing practice and began to delineate clusters of competencies called domains that are widely accepted as essential to modern nursing practice [25].

Even though nursing has generally embraced Benner's work, the profession continues to be dogged by the perception by the public, health care workers, policy makers and administrators, and even nurses themselves as having the distinction of being the most honest, altruistic and trustworthy members of the health team. Nelson and Gordon further claim that nurses have been denied status, respect and self-esteem that flow from discipline specific cognitive skills, nurses have been socialized to believe that they gain respect for their virtuous qualities, rather than their knowledge. In order for nurses to play a meaningful role in the health care system that utilizes their full scope of practice, there must be a change in perception from nursing whose major contribution is that of altruism to one that recognizes nurses for their knowledge and skill [25].

\section{EXPANDING THE DEPTH AND RANGE OF REGISTERED NURSEDOMAINS OF PRACTICE}

There have been calls and some attempt to expand the scope of practice of RNs. This is a slow process in most regulatory jurisdictions, yet nurses are educated to provide a broader range of health services than they are allowed to provide either by employer restrictions or regulatory restrictions. Expanding on this notion, DavidsonDick contended that nurses are over-educated, learning to do more than the law permits them to do without scope of practice expansion. This state of affairs is illogical and reflects a hospital organizational mindset that does not support higher education for nurses. Educators are caught in the dilemma of training inquiring minds to assess, question, and intervene, while preparing nurses to work in a system where most decision-making about patient care is physician driven, or above their pay grade [26]. Most nurses are not permitted to work to the fullness of their present roles; yet, RNs have pushed the limits of their practice at times in areas where services of physicians were not available, or physicians did not want to practice [27]. Physicians have, on one hand, opposed a broader scope of practice for nurses in urban areas while, on the other hand, supported the notion for nurses working in rural and remote areas [28].

The College Registered Nurses of British Columba (CRNBC) listed an expanded RN practice in their Scope of Practice guidelines, which allows RNs to practice certain functions under specified conditions [29]. In 2012, the Saskatchewan Registered Nurses Association initi- 
ated a project called "Optimizing the Scope of Practice" which sought to licence RNs to perform specific authorized functions in some geographic areas of the province [30]. This project can be a first step in changing the RN scope of practice, albeit it is presently limited to a small number of RNs.

\section{METHOD}

The purpose of this research was to gain insight into the range and depth of nursing domains that are uniquely that of a registered nurse. Interpretive description is the research methodology used because it is congruent with the specific disciplinary requirements for nursing knowledge development by illuminating the practice of the RN by highlighting the domains of practice [31]. Interpretative description allows the researchers to organize data around a disciplinary conceptual framework that is practice based, and use knowledge from available empirical evidence. Interpretive description constitutes a method that generates questions from a disciplinary perspective in a logical, systematic and defensible manner and "creates the context in which engagement with the data extends the interpretive mind beyond the self-evident to see what else maybe there" [31].

Focus groups were used for data collection in preference over individual interviews as the dynamic interplay between nurses was an integral part of the process of articulating the domain of nursing practice as it is now. To gain insight into the depth and range of nursing domains unique to RNs, the interaction of participants in "group think" was a key factor in selecting this method. In addition it is an efficient way to collect data from a number of nurses [32]. Embedded in this research approach is the process whereby researchers invite potential participants with similar experiences to come together, share information and exchange ideas. The social dynamic is the foundation of the focus group. Participants tend to bring a sense of clarity and affirmation of the elements of the common experience that are not easily articulated by individuals in isolation. The focus group with its emphasis on social dynamic is appropriate, as many nursing actions, functions, and underlying knowledge are not visibly apparent to onlookers or even some RNs.

While focus groups were used to gain insights and perceptions about RN domains of practice and the deeper meanings nurses attach to their practice, qualitative analysis using the interpretive description underpinnings was used to gain a perspective of the range and depth of registered nurse domains of practice. A thematic analysis was conducted in which themes were uncovered in the focus group data, and then essential themes were determined [33]. Through interpretation and writing the text, researchers sought to understand how the context of nursing practice is played out by individuals sharing their experiences to build understanding of essential themes in the domains of nursing practice [34].

Researchers obtained ethical approval from two university research ethics boards. Eligible participants were nurse leaders working in government, healthcare organizations, and nursing education programs for the first set of focus groups, and registered nurses working directly with patients for the second set of groups. Participants responded to widely circulated invitations to attend and participate in crucial conversations with peers about RN practice. In the first set of focus groups, 39 nurse leaders employed in rural and urban areas of the province came together, signed consents to participate, and participated in study discussions with peers. Throughout the course of a structured gathering, nurse leaders had opportunities to join group discussions with peers, exchange knowledge in response to semi structured questions, and in-between discussions, listen to three presentations. In one presentation, information was provided by the province's chief nursing officer about the number of nurses employed where, and in what capacity in the province; another presenter described a nurse-staffing model used to ascertain what category of nurse is needed to provide nursing care for complex patients in hospitals; and a third nurse presented about a nursing intervention classification system used to describe required nursing interventions for patients with various health challenges. In the second phase of this study, front line nurses working in rural and urban healthcare workplaces were invited by their nurses' union to attend a research and knowledge exchange gathering to discuss RN practice. Forty-two nurses attended. Following a brief presentation about the purpose of the research, all attendees voluntarily signed consents to participate in focus groups about their scope and domains of nursing practice.

Participants at each gathering were asked to take a seat with up to seven other participants at a table of their choice, and each table-group of participants were asked to answer semi-structured questions by sharing experiences that they wished to share and that best illustrated their perspectives. At each table, a within-group participant recorded quotes, brief stories, and consensus points with pen and paper as participants shared their experiences depicting the range and depth of $\mathrm{RN}$ domains of practice. Papers with recorded stories were gathered as data by researchers when groups signalled that they had illustrated answers to questions to their satisfaction in their group. Researchers identified rudimentary themes from the papers shared by groups, and presented these initial "stand out" themes back to the participants. Participants viewed, refined and verified that thematic groupings of threads from their stories were consistent 
with their shared perspectives as emerging themes. The researchersmet to further discuss initial themes from each gathering, and engaged in thematic analysis as a fluid process, including ongoing reflection of meanings of participants' stories and linkages with emergent themes in light of previous literature and the current $\mathrm{RN}$ work climate in the province.

\section{FINDINGS}

Although participants in each gathering and phase discussed a broad range of experiences and issues facing healthcare workers and specifically RNs, the focus of this paper is to report on RN domains of practice identified. Legislation authorizing nursing self-regulation provides RNs with the parameters for their practice shaped by their education and experience, competency, and the nature of the practice setting. In our changing healthcare system, the professional role of RNs can be indistinguishable from other nursing and health care providers' roles, for patients, providers, employers and policy makers. Themes illustrate the priorities and extent of care RNs currently provide and foresee need for in the future.

\section{NURSE LEADERS' PERSPECTIVES OF REGISTERED NURSE DOMAINS OF PRACTICE}

Eight major themes emerged from nurse leaders' discussions. Themes illustrate current and potential RN roles in healthcare settings.

Theme 1: RNs must voice and articulate the extent of their practice to patients, the public and policy makers.

Participants expressed that registered nurses must speak up and articulate the RN scope of practice to patients, the public and policy makers in a professional manner. One participant commented "RNs have been too silent, too passive, too nice for too long. RNs have to see themselves as professionals, speak as professionals on the issues, and be seen as RNs first and employees second”. Another participant stated:

"It is not a surprise that patients' and the public's image of RNs have been lost. We need RNs to recognize and get out from under what they think of as oppressive conditions, gain confidence in defining our roles in patient teaching, advocacy, policy, patient discharge planning, and start to become more vocal, or RNs will not be valued and respected, they will not be able to make a difference for patients; RNs will fade into the backgrounds”.

In addition to becoming more thoughtfully vocal, nurse leaders urged RNs to become more politically astute and gain understanding of employers' and government policy regarding $\mathrm{RN}$ practice.

Theme 2: RNs advocate for patients and families.
Nurse leaders acknowledged that RNs advocate for patients' and families' care continuously:

"RNs continue to advocate for patients, not blaming or accusing patients for their problems, but advocating for prevention and professional responsibility. RNs are already advocates for patient safety at the point of care.” Participants did however advise RNs to:

"RNs need to kick it up a few notches, advocate at a policy level with a patient-first focus for better care, for primary health care, because RNs haven't changed their advocacy script as unions and professional associations in years, it is the same-old, same-old message."

Theme 3: RNs are leaders and collaborators.

Nurse leaders viewed RNs as leaders in healthcare, asserting that RNs are leaders whether they work as care givers with patients and families, as educators, care coordinators, or in collaboration with other healthcare managers. A quote to illustrate this perspective:

"RNs in the province need to be included and participate at decision making tables to have impacts on policy decisions and directions. There are more RNs in 'power' positions in regional health authorities, as chief operating officers, vice presidents, chief nursing officers, and in government than ever before."

RNs were seen as leaders and collaborators as RNs coordinate care for patients, collaborate with patients, families, and other caregivers to facilitate smooth transitions in care, and form collaborative partnerships with other health care workers (physicians, health care providers, managers, support services). RNs collaborate as employees, members of unions, and professional associations.

Theme 4: RNs have a role in shaping healthcare culture and forming relationships.

Nurse leaders noted that there has been a shift in healthcare culture "at the ground level". Visible interactions between healthcare workers and in particular, between and among nurses may be positive or negative (one participant identified this as "lateral violence"). Nurses assume they have a trust relationship with patients and families, however this relationship must be consistently established and nurtured, and not taken for granted, neglected, or abandoned. One nurse leader participant observed:

"Nurses are often in a position of power with patients in hospitals by virtue of the fact that they are healthy and present, although not so much in the community. Nurses have to establish trusting relationships and maintain these (emphasis) with honesty, respect, and accountability, or risk losing ground with patients, families, and other health care providers."

Nurse leaders came together to express hope that:

"RNs would use their collective power towards building positive environments, rather than simply 'going 
along to get along in the workplace' because collectively RNs have the knowledge, skill, judgement and influence to achieve innovations by focusing on providing high quality patient and family care.”

Theme 5: RNs Roles may change with patient acuity and complexity, and changing work environments.

Patients need nursing care for many complex conditions. RNs are educated and prepared to provide holistic care for patients. Unfortunately, some RN roles are adversely affected by:

"Challenging work conditions, rapid turnaround of patients, less time and receptivity of co-workers to discuss patient issues, and work conditions that impact job satisfaction and quality of care.” Nurse leader participants questioned:

"Are the right care providers providing the right care for this patient, is the person receiving holistic care or just having tasks completed by people that 'helicopter in' and leave?” There was an underlying sense of urgency that RNs need to come together to assess, plan, implement and evaluate care for each person, and perhaps adjust their roles to solidify a patient and family focus rather than allowing:

"The pressures and busyness of the work environment to reduce nursing roles into just 'tasks' that have to be done, by anyone who is there."

To adjust and adapt to changing roles, supportive environments for RNs are needed:

"Now more than ever, hospitals need available and engaged RN managers who are not buried in administrative duties, as well as environments where people want to work, which reflects the quality of the workplace.”

Theme 6: RNs Roles are embedded in practice, and RNs use care delivery models.

Participants eloquently stated:

"RNs define their role consistent with their area of practice, RNs have a strong role in health promotion and disease prevention, and may even be the primary assessor for patients to enter the health care system. RNs will be essential to help patients navigate through the system as RN case managers."

"RN roles are embedded in practice: they will always focus on patient-centred care, but may have expanded roles in emergency departments, expanded educator roles, be co-ordinators of care, may have expanded roles in self help groups, committees, and with projects. RNs can develop and use care plans that really work, and RNs don't get bogged down when a patient doesn't meet the target for Day 3 on a care pathway. RNs may have roles in training the trainer for other RNs and healthcare workers."

Theme 7: RN Roles in education, research and management of resources.

Nurse leaders viewed $\mathrm{RN}$ roles in education, and
RNsoccasionally participate in a research study, and consider evidence from patient preferences or evidence that was readily available. In future, RNs roles in education will expand with RNs educating other RNs and healthcare workers, patients, families, and communities. Participants stated:

"RNs now are noticing a disconnect between education and the reality of practice; this may be due to beginning graduates having more knowledge, and their eagerness to use evidence, capture and write research, and translate knowledge to practice."

"RNs will be increasingly interested in use of current evidence to care for patients, and measuring and comparing outcomes from care. This will increase RN use of evidence and generation of research to answer the questions of nurses in practice and advance nursing knowledge. RNs will be called upon to prioritize, support, and encourage professional development of their colleagues, to fill gaps in skills sets, and develop expert practitioners."

A participant predicted that with a cash-poor healthcare system:

"RNs will be responsible to find efficiencies so there is time to do what needs to be done to advance patients' health, this may mean redistributing human and material resources."

Theme 8: RNs use technology.

Technology advances were increasing the necessity to use technology; most RNs did not regard technology as possibly replacing RNs at work; rather RNs wanted technology to be used safely and effectively for patient care. RNs roles included using technology appropriately and collaborating to define what "appropriate means to different generations of nurses." A participant commented:

"RNs must work together to use technology in their workplace and develop healthy policy around technology use."

A barrier to the use of technology identified by nurse leaders was the perception of the abuse of technology, and an assessment that some RNs are: "late adopters of technology, because they avoid it."

Themes from nurse leader participants illustrate RN scope of practice as the depth and breadth of knowledge, skill and judgement embedded in RNs roles and domains of professional practice.

\section{REGISTERED \\ NURSES'PERSPECTIVES ABOUT REGISTERED NURSEDOMAINS OF PRACTICE}

Registered nurse participants shared stories of their realities and future predictions for $\mathrm{RN}$ roles and scope of 
practice.

Theme 1: RNs must portray professional RN roles and image (to patients, the public and policy makers).

Registered nurse participants were aware and vocal in describing that not all RNs portray a professional image and provide nursing care in a professional way. With plenty of discussion of 'not so good' experiences one RN participant stated:

"As RNs we are responsible individually and collectivelyto communicate our depth and breadth of knowledge. Our roles are more than completing tasks, we take a holistic view of patients and families with our assessments, use the nursing process when planning for care for our patients, we check and administer medications that we know the patients must have, and we consider individual patients' families, religions, losses, and enrichments that are possible with the care we give. In addition to this, we have to be conscious of how we convey our professional roles and portray the image of a registered nurse when we are at work and in the community."

"Maybe because our manager does not know, but maybe its because no one seems to know our RN practice-there is a lot of role confusion out there, and other health care providers are doing our jobs. We need to stand up and tell others that as RNs, we know the organization is dependent on each group of providers working together in a professional manner and functioning to their own scope of practice for the benefit of the patient."

Theme 2: RNs advocate for patients and appropriate patient care.

Nurse participants voiced they felt responsible:

"RNs are responsible to guide clients through the health care system and coordinate the health care team to benefit patients, from time of initial assessments to time when a patient no longer needs nursing care. When there is talk about care teams, the RN is the one to do the referrals, monitoring and follow up."

"What is the unique role of the RN? Advocacy for the patient, seeing the whole patient, the entire picture, not just a job to do, assessing in everything we do, we don't even realize we are doing it, and unfortunately, neither does anyone else."

Theme 3: RNs are leaders in health care settings.

Front line nurses recognized that RNs are leaders in a variety of health care settings:

"In workplaces where there is an RN working, it is the RN who makes decisions, takes charge, takes responsibility, without even really thinking about it, it is second nature to our role. We have increased responsibility due to the way RNs practice with increased workloads, increased patient acuity, pressures to keep within budget, and RNs wanting to make sure the patients receive holistic care. RNs see what is needed and will move heaven and earth to try to make it happen for patients, but have not figured out how to make it happen for all RN practice."

"We (RNs) coordinate the team in health care, guide clients through the system, we are innovators, educators, facilitators, schedulers, teachers, mentors, and all round care givers for the patient, family and community."

Theme 4: $R N$ scope of practice must expand to meet health care needs of the public, especially in rural and remote areas.

Nurse participants articulated clearly that the health care system was changing rapidly, and there were areas where RN scope of practice needed to expand:

"More nurses are working in isolated environments, and they must be independent due to geography, populations they work with, and the programs and clinics where they are the only nurse. We need greater autonomy in decision making about patient care based on our nursing assessment, and the ability to refer the patient to an appropriate care provider."

"We are going have to expand RN scope of practice, for instance we need to increase our skill set in some areas such as suturing, or inserting arterial lines, there is a need for RNs first-assist in operating rooms and minor trauma/treatment centres, we could help health care organizations if RNs could discharge patients based on specific criteria, when we are assured they have the knowledge and can access care for themselves at home."

"We must have more autonomy in our practice, and we need clarity and definition of RN scope of practice at the point of care to make it truly patient and family centred care. We need to be able to order routine diagnostic tests such as ECGs for a person with chest pain, or $\mathrm{X}$-Rays for probable limb injury, or a swab of a wound for culture and sensitivity, a urinalysis or urine culture. The list must include dispensing some common medications such as Tylenol for a headache."

Theme 5: RNs are knowledge workers, educators and preceptors.

Nurses valued their roles as knowledge able professionals, educators, mentors and preceptors of beginning nurses:

"We (RNs) have to overcome barriers and keep abreast of new knowledge and evidence to enhance and support patient recovery. We need to participate in education days, learn more, use evidence to care for patients, mentor new nurses, and be preceptors when we are offered the chance."

"I would like to see education opportunities where we work, sometimes RNs in hospital get education if they happen to be working and able to attend, but other RNs don't have access to employer funded education sessions."

Theme 6: RNs assess health status, anticipate care 
required, plan and co-ordinate care for patients and families.

Many RN participants told stories about their experiences providing nursing care to unnamed patients and families. Participants affirmed the dedication and commitment of RNs to patient and family centred care:

"It is essential to have an RN assess, plan and provide care for patients with complex needs. Here is just a little example, I was listening to report and an LPN told me she decided not to wake up a patient for 'glaucoma drops' because the patient had her eyes closed. I wondered if this person knew what the eyedrops were for, and the consequences of not administering them for the patient? I wondered what other care was skipped, and I am not saying this happens all the time, but RNs know why we give medications and anticipate care.”

\section{DISCUSSION}

In light of our findings, describing the depth and breadth of RN practice is harder than we anticipated. We gained a clearer picture of how nurse leaders and registered nurses see current RN practice domains and roles and envision future RN practice. The RN roles identified by practicing RN participants were similar but not completely congruent with what nurse leaders perceived as $\mathrm{RN}$ roles. A different approach might be to focus on RN role development, and describe roles for nursing practice as rather than a one-size-fits-all RN scope of practice. Merits of RNs focusing on education for and development of specific roles are that RNs will not be hampered by their inability to articulate their practice, rather, RNs could confidently state they are nurse leaders, educators, nursing care providers, mentors, or identify the main role of their nursing practice. A disadvantage of this approach is that RNs would require a high degree of judgement to determine the outer limits of RNs roles and would rely heavily on continuing competence assurance for practice and RN code of ethics to maintain professional standards.

An umbrella regulatory organization that brings all nursing organizations to the table to make decisions on practice issues, authorized functions, and roles is essential. A major barrier to regulatory reform exists with the regulatory bodies, who may fear losing some existing authority. There is benefit for government and employers of maintaining the status quo of multiple regulatory bodies debating nursing scopes of practice for all categories of nurses, as amidst a chaotic environment with conflict between nursing regulators with multiple competing interests, organizational health care changes are easier to implement.

We found little appetite amongst practicing RNs or nurse leaders for turning back to the previously circum- scribed nursing process in which RN had exclusive scope of practice, as all nursing legislation needs to reflect modern practice. Changes in nursing legislation which defines scope of practice do not always reflect nor ease the relationship between roles of various nursing personnel. The RN scope of practice needs to integrate and state the functions of leadership and care coordination, patient advocacy and evidence-based care as these are essential roles of RNs in the modern health care system.

Mechanisms must be in place to allow RN role development within existing health care organizations and systems. Changes to nursing practice tend to take place slowly with the convoluted process of updating legislation, and lack of a clear articulation of the depth and breadth of knowledge required for increasing the scope of practice of different levels of nursing personnel. In addition, a deeper understanding of the $\mathrm{RN}$ role by registered nurses, health team members, administrators, policy makers and the general public is required. There must be methods of ensuring that registered nurses can apply their knowledge, skills and judgement in meaningful ways when changes occur in health care practice.

A major issue is to educate all RNs about meaningful ways to articulate the knowledge required for their practice to patients, families, administrators, and policy makers. They need to ensure patients and decision makers understand the critical nature and value of their work. This is a massive goal, in our publicly funded health care systems the financial picture is often tight, and governments, taxpayers and decision makers tend to look at highly visible patient care tasks, rather than the critical cognitive and decision-making functions that underpin execution of tasks. Employers frequently anticipate what nursing work must be completed and tend to focus on tasks, rather than the knowledge and judgements required for high quality patient care. This situation can be demoralizing for front line registered nurses who bear the brunt of the role change, loss of employment, and redundancy. Close cooperation between regulatory bodies, nursing schools, professional bodies and nurses' unions to ensure a sustained consistent approach in providing RNs with the knowledge and skills to effectively articulate the critical nature of their work.

A meaningful role for RNs is necessary in order to best serve patients, the health care system and for the continued development of the various categories of nurses. The efforts to develop advanced practice roles and modernize LPN scope of practice have received a lot of attention, yet the RN scope of practice has remained static. Clarity in roles, domains of practice, and relationships between categories is imperative to realizing this goal. Failure to focus on this issue could have an untoward impact on the health care system and the nursing profession. 


\section{ACKNOWLEDGEMENTS}

This research was conducted using grants from the University of Saskatchewan Research Accelerator Program, the University of Saskatchewan Conference Fund \& the Saskatchewan Health Research Foundation Conference Fund. The Saskatchewan Union of Nursing provided in kind support for this project.

This research received ethical approval from the University of Saskatchewan Ethics Board and the University of Regina, Research Ethics Board.

Funding for Open Access provided by the University of Regina Library Open Access Fund.

\section{REFERENCES}

[1] Fry, B. (2013) Get the job done: Straight talk about scope of practice. Canadian Nurse, 109, 32-33.

[2] Canadian Nurses Association (2007) Framework for the practice of registered nurses in Canada. Ottawa.

[3] College of Registered Nurses of Manitoba (2008) Fact sheet determining the scope of practice of an individual registered nurse.

http://www.crnm.mb.ca/memberinfo-scopeofpractice.php

[4] College of Registered Nurses of Manitoba (2010) Understanding scope of practice for licensed practical nurses registered nurses registered nurses in the province of Manitoba.

http://cms.tng-secure.com/file_download.php?fFile_id=1 0231

[5] Baranek, P.M. (2005) A review of scopes of practice of health professions in Canada. A balancing act. Health Council of Canada, Toronto.

[6] West, E.A., Griffith, W.P. and Iphofen, R. (2007) A historical perspective on the nursing shortage. Medsurg Nursing, 16, 124-130.

[7] Yam, B.M.C. (2004) From vocation to profession: The quest for professionalization of nursing. British Journal of Nursing, 13, 978-982.

[8] Schlotfeldt, R.M. (2002) Structuring nursing knowledge: A priority for creating nursing's future. In: Kenney, J., Ed., Philosophical and Theoretical Perspectives for Advanced Nursing Practice, 3rd Edition, Jones and Bartlett Publishers, Sudbury, 5-9.

[9] Kilstof, K. and Rochetser, S. (2004) Hitting the ground running: Transitional experiences of graduates previously trained as enrolled nurses. Australian Journal of Advanced Nursing, 22, 13-17.

[10] Blais, D. (2007) Frequently asked questions about the RN scope of practice. Vancouver Island Health Authority. http://www.viha.ca/NR/rdonlyres/6F24A53D-DA92-4D2 8-9489-8D55163F2194/0/faq_rn_scope_of_practice_faqs _about_practice_march_21_07.pdf

[11] Board of Registered Nurses of California (1997) An explanation of the scope of nursing practice, including standardized procedures. http://www.rn.ca.gov/pdfs/regulations/npr-b-03.pdf

[12] Nurses Association of New Brunswick (2009) Working together: A framework for the registered nurse and licensed practical nurse. Author, Fredericton.

[13] College of Registered Nurses of British Columbia (2008) Working together for client safety. Vancouver.

[14] College of Nurses of Ontario (2009) Practice guideline: Utilization of RNs and RPNs. Toronto.

[15] Registered Psychiatric Nurses Association of Saskatchewan, Saskatchewan Association of Licensed Practical Nurses, \& Saskatchewan Registered Nurses Association. (2000) Nursing in collaborative environments. Regina.

[16] Canadian Health Services Research Foundation (2006) Staffing for safety: A synthesis of the evidence on nurse staffing and patient safety. Ottawa.

[17] Gaudine, A.P. and Beaton, M.R. (2002) Employed to go against one's values: Nurse anagers' accounts of ethical conflict with their organizations. Canadian Journal of Nursing Research, 34, 17-34.

[18] Swan, B.A., Conway-Phillips, R. and Griffin, K.F. (2006) Demonstrating the value of the $\mathrm{RN}$ in ambulatory care. Nursing Economics, 24, 315-322.

[19] Ringerman, E. and Ventura, S. (2000) An outcome approach to skill mix change in critical care. Nursing Management, 31, 42-46.

http://dx.doi.org/10.1097/00006247-200010000-00022

[20] Besner, J., Doran, D., McGillis Hall, L., Giovannetti, P., Girard, F., Hill, W., et al. (2005) A systematic approach to maximizing nursing scopes of practice. CIHR, Calgary.

[21] Clarke, S. (2013) From the ground up. Canadian Nurse, 109, 20-24.

[22] Clarke, S. and Aiken, E. (2006) More nursing, fewer deaths. Quality and Safety in Health Care, 15, 2-3. http://dx.doi.org/10.1136/qshc.2005.017343

[23] Benner, P., Sutphen, M., Leonard, V. and Day, R. (2010) Educating nurses: A call to radical transformation. A Wiley Imprint, San Francisco.

[24] Nelson, S. and Gordon, S. (2006) The complexities of care: Nursing reconsidered. ILR Press, Cornell.

[25] Benner, P. (1984) From novice to expert: Excellence and power in clinical nursing practice. Prentice Hall, Upper Saddle River.

[26] Davidson-Dick (1991) Interview with Sarah Growe. In: Growe, S., Ed., Who Cares? The Crises in Canadian Nursing, McClelland \& Stewart, Toronto.

[27] Saskatchewan Union of Nurses (1998) Spectrum: The future of nursing? Regina.

[28] Evans, C., Jones, L., Way, D. and Paes, B. (1997) Is there room for both NPs and MDs. In: Patterson, C., Ed., Visions and Voices: The Nurse Practitioner Today, Lugus Publications, Toronto, 101-149.

[29] College of Registered Nurses of British Columbia (2010) Scope of practice for registered nurses: Standards, limits \& conditions. Vancouver.

[30] Saskatchewan Registered Nurses Association (2012) Optimizing scope project. Regina.

[31] Thorne, S. (2008) Interpretive description. Left Coast Press, Walnut Creek. 
[32] Fain, T. (2008) Reading, understanding, and applying nursing research. 4th Edition, F. A. Davis, Philadelphia, 182-183.

[33] Garrick, J. (1999) Doubting the philosophical assumptions of interpretive research. Qualitative Studies in Edu- cation, 12, 147-156.

http://dx.doi.org/10.1080/095183999236222

[34] Van Manen, M. (1990) Researching the lived experience: Human sciences for an action sensitive pedagogy. The Althouse Press, London, 78-135. 